\title{
Effects of Cardio-Pilates Exercise Program on Physical Characteristics of Females
}

\author{
Dilek Sevimli $^{1, *}$, Murat Sanri $^{2}$ \\ ${ }^{1}$ Department of Physical Education and Sport, Coaching, Çukurova University, Turkey \\ ${ }^{2}$ Department of Physical Education and Sport, Çukurova University, Turkey
}

Copyright $\mathrm{O} 2017$ by authors, all rights reserved. Authors agree that this article remains permanently open access under the terms of the Creative Commons Attribution License 4.0 International License

\begin{abstract}
Aim: This study aims to investigate to effects of four weeks cardio-Pilates exercise program on physical characteristics in females. Material and methods: The total 40 female participants were tested before and after four weeks regular exercise of $3 \times 1 \mathrm{hr}$. sessions/week. Body height and weight, waist and hip circumferences, body fat percent and weight were measured. To test the differences, a paired t-test was used. Results: This study showed that cardio-Pilates exercise program significantly decreased body fat percent, body fat weight, waist and hip circumferences. Cohen's d calculations showed that four weeks exercise program had a significant moderato effect on body fat percent, body fat weight, waist and hip circumferences in females. Conclusion: Four weeks exercise program seems to be effective in decreasing the body fat and circumference values in females. It was concluded that the magnitude of training effect depends on the duration and intensity of the exercise program.
\end{abstract}

Keywords Physical Characteristics, Female, Cardio-Pilates

\section{Introduction}

Pilates was first developed by Joseph Hubertus Pilates as an exercise method that improves body posture and increases body awareness. The method was mainly based on mind-body-soul theories of the East and bio-mechanic, motor learning and body stabilization theories of the West [1, 2]. Pilates, which can be done with or without equipment, is a popular exercise that has plenty of varieties consisting of exercises of isometric contraction that are easy to control at low frequencies and improve skeleton-muscle system [3].

Cardio-Pilates is an abbreviated term used for the word "cardiovascular", which refers to circulation system including heart and veins. "Cardio" is a general term used for all exercises that activate cardiovascular system. These exercises are preferred usually to burn calories, fat and to maintain body weight. Pilates exercises, which improve muscle strength and resistance, are the exercises done on a mat and used together with cardio exercises for waist, hip, legs, back and arm muscles.

In line with its increasing popularity in media, there have been a lot of studies in the field of training sciences conducted on Pilates. These studies have usually focused on methods of Pilates and its effect on coordination motor skills such as strength, agility, flexibility and endurance [2-4]. Also, there are studies conducted to investigate the impact of Pilates exercises on body awareness, control and correct muscle activation $[5,6]$.

Segal et al. investigated the effects of Pilates exercises on anthropometric variables of 47 healthy participants (45 females and 2 males) for 6 months and found out statistically insignificant changes in BMI and body weight of the participants [7]. In another study, Jago et al. searched for the effects of Pilates exercises on body composition of the participants that consisted 30 participants, 16 girls aged 10-12 and 14 adults, after an hour of five-time a week program lasting four weeks. The results of their study showed that there was 0.8 increase in the control group's BMI percentages while they found 3.1 increase in those of Pilates group's. Recent studies indicate that Pilates exercises are increasing in popularity as a preventive exercise type against obesity, which is a common health problem of the modern world [8]. Cakmakçı [9] calculated body mass, waist circumference and waist/hip ratio variables in 58 sedentary obese women. In the study, the participants in the experimental group $(n=34)$ participated in 8 -week Pilates program with Pilates ball and mat exercises while the control group $(n=27)$ did not do any exercises. The Pilates program was held 4 times a week for an hour. The results indicated that Pilates program with Pilates ball and mat exercises helped reduce obesity in obese sedentary women and led to significant changes in flexibility parameters [9].

Inactivity is more common among high-income women than it is among high-income men in the world. Compared 
to young women, older women are less active around the world and this difference has been increasing[10]. In Turkey, the rate of inactive people is about $80 \%$ of the whole population [11]. As the number of illnesses related to inactivity is on the rise in our country, inactivity has becoming the lifestyle of especially adult women.

There are a significant number of studies in literature investigating the morphological and physiologic effects of exercises on males and females with various durations, type, frequency, and intensity of exercise programs $[2,7]$. These studies mostly investigated the impacts of 3-4 weeks of exercise programs $[12,13]$. For example, the study conducted by Wanderley et al [12] searched for the effects of three-week exercise program on the elderly and found no significant impact [12]. Sartorio et al. found out significant effects of four-week program combining aerobics, strength exercises and diet on 61-75 years old obese women's body weight, body composition, and physical performance [13]. Both of these studies were conducted with old people. In our study, we focus on the effects of four-week cardio-Pilates exercise program on middle-aged females' body composition variables. It also aims to determine the shortest duration for such an effect.

Therefore, the present study aims to find out the effects of four-week cardio-Pilates exercise program on middle-aged women's physical characteristics.

\section{Method}

\subsection{Participants}

The volunteering female participants were between the ages of 25-41 and had 38.30 \pm 11.04 mean age, $161.43 \pm 8.18$ $\mathrm{cm}$ mean height, and $68.98 \pm 11.04 \mathrm{~kg}$ mean weight. The study included the participants who had no health problems and joined the four-week Pilates exercise program which lasted 60 minutes and three times a week (Monday, Wednesday, Friday) done at the same time of the day. Pilates exercise program, confirmation forms, demographic information of the participants and pre/posttest calculations were conducted and recorded at Cukurova University Fitness Center in March 2016.

\subsection{Exercise Procedure}

Warm-up: The program had 10 minutes of warm-up session consisting of 5 minutes general warm-up for major muscle groups and 5 minutes of stretching and strength exercises.

Main Phase: For cardio exercises, participants did 20 minutes of aerobics exercises standing that included mostly leg and arm activities accompanying with music was conducted. This phase was diversified via steps, simple forms, and short figures to improve sense of rhythm and coordination. During this phase, the pulse was kept between
100 and 120.

Pilates-Mat exercises lasted 20 minutes and included repeated 3 -set $(1 \times 10 ; 1 \times 12 ; 1 \times 15)$ exercises aiming major muscles, abdomen, hip, waist, leg, back, chest and arm muscles.

Cooling: The cooling phase was the last one and continued for 10 minutes. During this phase, 5 minutes of general cooling exercises and 5 minutes of stretching and breathing exercises were conducted.

\subsection{Instruments}

The participants' heights were measured by stadiometre (Holtain, UK) on nude foot and the weights were measured by electronic scale (Seca, Germany) while the participants wearing shorts and t-short. For measuring BMI, body weight (as kilogram) is divided into square of height (as meter).According to BMI, thin $(<18.5)$, moderate weight (18.5-24.9), overweight (25-29.9) and obese (30.0) values were applied. Waist circumference was calculated using non-flexible millimeter tape measure from lower rib and cyrictialliac. Hip calculation was done at the same time from maximum hip circumference. Following these, body weight and composition values were obtained via bio-electric impedance analysis (Tanita Body Fat Analyzer, model TBF 300 ) as the participants were in a bare-foot standing position and wore light cloths. The scale used in the study had $0.1 \mathrm{~kg}$ sensitivity. Body fat percent and body fat mass were calculated using bio-electric impedance Tanita analysis.

\subsection{Data Analysis}

The data was analyzed using SPSS 20.00 program. For pre-test and posttest measurements, independent groups t-test and Cohen's d was calculated. Cohen's d, which was used to determine the effect size, is considered to have low effect size if it is lower than 0,2 , to have a moderate effect size if it is between 0.2 and 0.8 , and to have a high effect size if it is above 0.8. However, there are some specific cases where 0.2 is still considered to have a significant effect size $[14,15]$.

\section{Findings}

The female participants' physical characteristics are displayed in Table 1. For determination the effect of training, body weight decreased from $68.98 \pm 11.04 \mathrm{~kg}$ to $67.37 \pm 11.37 \mathrm{~kg}$; BMI decreased from $26.56 \pm 4.57$ to $25.94 \pm 4.68$ in pre-test and post-test values. The mean score for body fat percentage decreased from $33.00 \pm 4.50$ to $31.54 \pm 4.72$. Also, total body weight decreased from $23.39 \pm 6.94 \mathrm{~kg}$ to $21.80 \pm 6.69 \mathrm{~kg}$ as waist circumference decreased from $91.03 \pm 8.85 \mathrm{~cm}$ to $88.81 \pm 9.41 \mathrm{~cm}$. Hip circumference declined from $105.60 \pm 7.73 \mathrm{~cm}$ to $102.68 \pm 7.59 \mathrm{~cm}$. Furthermore, waist/hip ratio was $86.25 \pm 6.33$ for pretest and was $86.48 \pm 6.35$ for posttest. 
Table 1. Comparison of Women's Physical Characteristics between Pre- and Post-Four Week Cardio-Pilates Exercise Program

\begin{tabular}{|c|c|c|c|c|c|c|c|c|}
\hline \multirow{2}{*}{ Variables } & \multicolumn{2}{|c|}{ Pre test } & \multicolumn{2}{|c|}{ Post test } & \multirow{2}{*}{ Diff } & \multirow{2}{*}{$\%$ Diff } & \multirow{2}{*}{$t$} & \multirow{2}{*}{ Cohen's $d$} \\
\hline & $M$ & $S D$ & $M$ & $S D$ & & & & \\
\hline Body Weight (kg) & 68.98 & 11.04 & 67.37 & 11.37 & 1.61 & 2.46 & 10.232 & 0.144 \\
\hline Body Mass Index $\left(\mathrm{kg} / \mathrm{m}^{2}\right)$ & 26.56 & 4.57 & 25.94 & 4.68 & 0.62 & 2.46 & 9.923 & 0.134 \\
\hline Body Fat (\%) & 33.00 & 4.50 & 31.54 & 4.72 & 1.47 & 4.56 & $8.652 \dagger$ & $\dagger 0.312$ \\
\hline Body Fat (kg) & 23.39 & 6.94 & 21.80 & 6.69 & 1.59 & 6.69 & $5.177 \dagger$ & $\dagger 0.233$ \\
\hline Waist Circumference (cm) & 91.03 & 8.85 & 88.81 & 9.41 & 2.21 & 2.49 & $7.221 \dagger$ & $\dagger 0.243$ \\
\hline Hip Circumference (cm) & 105.60 & 7.73 & 102.68 & 7.59 & 2.92 & 2.76 & $9.528 \dagger$ & $\dagger 0.381$ \\
\hline Waist / Hip ratio & 86.25 & 6.33 & 86.48 & 6.35 & -0.23 & -0.29 & -.672 & -0.036 \\
\hline
\end{tabular}

Note-Cohen's $d . \dagger p<.05$.

The effect size of the program was calculated using Cohen's d for body fat percent, body fat weight, and waist and hip circumference and was found that the four-week exercise program had moderate effect size for these variables $(0.312,0.233,0.243,0.38$, respectively). When pre-test and post-test scores for body fat percent, body fat weight, and waist and hip circumference were compared, statistically significant differences were found.

For the variables of body weight with 2.46 average difference, BMI with 2.46 average difference, and waist/hip ratio with 0.29 average difference, it can be stated that the exercise program had low effect size (Table 1).

\section{Discussion}

Pilates exercises increases body awareness, posture control, correct muscle activation, and improve motor skills such as strength, flexibility, agility, and speed $[2,3]$. Recent scientific studies usually implement 6-8 weeks exercise programs that aim to improve body posture, muscle strength, back activation, body stamina, body composition and physical characteristics [16].Our study investigated the effects of four-week cardio-Pilates exercise program without a diet program.

The results of the study revealed that there were significant decreases in the participants' body fat percent, body fat mass, and waist/hip circumferences at the end of the four-week cardio-Pilates exercise program. However, no significant differences were found for BMI, body weight, and waist-hip ratios. According to Cohen's d values, the exercise program was moderately effective on the female participants' physical variables such as body fat percent, body fat mass, and waist/hip circumferences.

Cakmakç1 [9] implemented 4-day one hour long exercise program and did Pilates $(\mathrm{n}=17)$ with one group and Pilates-ball $(\mathrm{n}=17)$ with another group. The program lasted 8 weeks and included sedentary obese women. At the end of the study, it was reported that mat-Pilates and ball exercises decreased obesity and led to significant changes in body composition and flexibility parameters [9]. The results from Cakmakçı's study are only about body composition and indicate similar findings with our study, which lasted longer than one month. Also, the findings of our study are in line with the study conducted by Wolkodoff which reported significant changes of aerobics trampoline-Pilates exercises on body composition [17].

A number of studies in literature investigating the structural and physiologic effects of exercises on males and females with various durations, type, frequency, and intensity of exercise programs mostly focused on the impacts of 3-4 weeks of exercise programs. Although the study conducted by Wanderley et al. [12] found no significant effects of three-week exercise program on the elderly, Sartorio et al [13] reported significant effects of four-week program combining aerobics, strength exercises and diet on 61-75 years old obese women's body weight, body composition, and physical performance [13]. Both studies investigated the effects of short-term exercise programs on women's physical characteristics $[12,13]$.

The mean age of our participants is lower than those participated in three- and four-week exercise programs. Rather than searching for the effects of short-term exercise program on the elderly, our study focused on the effects on the middle-aged participants physical characteristics.

The results of our study are in line with the study conducted by Wanderley et al. that indicated significant effects of three-week exercise program on body composition but not on decreasing body weight [12]. The study conducted by Sartorio et al. indicated significant effects on both weight and composition; however their study combined four-week aerobics and strength exercise program with diet [13]. In our study, the participants were not asked to follow a particular diet.

A significant decrease in body fat in in this study can be explained by increasing metabolic fitness due to cardio Pilates. Pilates exercise is isometric strength exercises improving skeleton-muscle system [3]. Regular physical activity enhances metabolic fitness parameters including glucose tolerance, insulin sensitivity, and lipid metabolism. The body starts mobilizing stored body fat from fat cells and burning this fat for energy instead of glucose [18, 19, 20].Also, Pilates as a resistance training activities with increasing resting metabolism can increase lean muscle mass, reduce body fat, fortify bone, lower blood pressure, improve blood lipid and cholesterol levels, and enhance 
your body's ability to use glucose [21, 22]. So, participants could be to lose their body fat and to decrease the circumference with insignificant decrease in the mean value of their body weight.

There is a need for further studies that aims to increase awareness on the effects of various exercise programs on obese women's body weight, body fat rate, waist/hip circumference values.

Although Pilates exercise program has lower energy consumption rate than the rates suggested by the American Sports Physicians College [18] integration of cardio exercises provides moderate energy consumption rates, which is effective for a healthy life [23]. The impact of an exercise depends not only on its duration but on its frequency, type and exercising background of the participants as well $[16,23]$.

\section{Conclusions}

While cardio-Pilates exercise program had no effect on weight and BMI of female participants, it was effective on body fat rate and body circumference values. It should be noted that the effect of an exercise program depends not only on its duration, intensity, and type but also on participants' exercising background and their diet.

\section{REFERENCES}

[1] BD. Anderson, A. Spector. Introduction to Pilates-based rehabilitation. Orthop Phys Ther Clin North Am., 9(3):395-411, 2000.

[2] C. Lange, V. Unnithan, E. Larkam. Maximizing the benefits of Pilates-inspired exercise for learning functional motor skills. J Body MovTher., 4(2): 99-108, 2000.

[3] C. Wells, GS. Kolt, A. Bialocerkowski. Defining Pilates exercise: a systematic review. Complementary Therapy Medicine, 20(4):253-62, 2012.

[4] BS. Carr, J. Day Effect of directed spring guidance on rate of skill acquisition. JOSPT. 2004; (1): 34.

[5] Bernardo LM. The effectiveness of Pilates training in healthy adults: An appraisal of the research literature. J BodywMovTher., 4:106-110, 2007.

[6] M. Shedden, L. Kravitz. Pilates: A corrective system of exercise. ACSM Health Fitness J., 11(5): 7-12, 2009.

[7] NA. Segal, J. Hein, JR. Basford. The effects of Pilates training on flexibility and body composition: an observational study. Arch Phys Med Rehabil., 85(12): 1977-1981, 2004.

[8] R. Jago, L. Marielle, JM. Missaghian, T. Baranowski. Effect of 4 weeks of Pilates on the body composition of young girls. Prev Med., (42):177-180, 2006.

[9] O. Cakmakçi. The effect of 8 week Pilates exercise on body composition in obese women. Collegium Antropologicum, 35(4); 1045-50, 2011.

[10] CH. Pedro, LB. Andersen, C. Fiona, RG. Bull, W. Haskell, U. Ekelund. Global physical activity levels: surveillance progress, pitfalls, and prospects. Lancet. Physical Activity, 20-28. 2012.

[11] A. Çeker, R. Çekin, MA. Ziyagil. Regular physical activity stages of behavior change in women and men from different age groups. CBÜ Physical Education and Sport Sciences Journal, 8(1):11-20, 2015.

[12] FAC. Wanderley, J. Oliveira, J. Mota, J. Carvalho. Effects of a moderate-intensity walking program on blood pressure, body composition and functional fitness in older women: results of a pilot study. Arch Exerc Health Dis., 1(2):50-57, 2010.

[13] A. Sartorio, CL. Lafortuna, M. Massarini, C. Galvani. Effects of different training protocols on exercise performance during a short-term body weight reduction programme in severely obese patients. Eating and Weight Disorders, 8(1): 36-43, 2003.

[14] H. Yıldırım, S. Yıldırım. On hypothesis testing, confidence interval, effect size and noncentral probability distributions. Elementary Education Online; 10: (3)1112-23, 2011.

[15] J. Cohen. The analysis of variance. In statistical power analysis for the behavioral sciences (second ed.). Lawrence Erlbaum Associates.274-87, 1988.

[16] TP. Yamato, CG. Maher, BT. Saraigotto, MJ. Hancock, RW. Ostelo, CMN. Cabral. Pilates for low back pain. Cochrane Database of Systematic Reviews, (7):1-71, 2015.

[17] N. Wolkodoff. The fitness effects of a combined aerobic and pilates program: an eight-week study. Aero Pilates, Pro, XP 555 Study, 2008.

[18] C. Bouchard, RJ. Shephard, T. Stephens (Eds.). Physical Activity, Fitness, and Health: International Proceedings and Consensus Statement. Human Kinetics, Champaign, IL, 1994.

[19] CM. Shay, H. Ning, SR. Daniels, CR. Rooks, SS. Gidding, DM. Lloyd-Jones. Status of cardiovascular health in U.S. adolescents: Prevalence estimates from the national health and nutrition examination surveys (nhanes) 2005-2010. Circulation. 127:1369-76, 2013.

[20] S. Brage, N. Wedderkopp, U. Ekelund, PW. Franks, NJ. Wareham, LB. Andersen. Features of the metabolic syndrome are associated with objectively measured physical activity and fitness in Danish children: The European Youth Heart Study (EYHS). Diabetes Care. 27:2141-8, 2004.

[21] E. Artero, D. Lee, C. Lavie, V. España-Romero, X. Sui, T. Church, S. Blair. Effects of muscular strength on cardiovascular risk factors and prognosis. J Cardiopulm Rehabil Prev. 32:351-358, 2012.

[22] B. Hurley, E. Hanson, A. Sheaff. Strength training as a countermeasure to aging muscle and chronic disease. Sports Med. 41:289-306, 2011 .

[23] LS. Pescatello. ACSM's guidelines for exercise testing and prescription /. Eds. Arena R. Riebe D. Paul D. Thompson PD. 9th ed. American College of Sports Medicine. Philadelphia: Williams\& Wilkins. pp.39-107, 2014. 